\title{
O acesso do estudante surdo em Instituições Federais de Ensino Superior no município de Salvador: o caso da Universidade Federal da Bahia (UFBA)
}

Deaf student access to Federal Higher Education Institutions in the municipal district of Salvador: the case of the Federal University of Bahia

El aceso de estudiantes sordos en Instituiciones Federales de Ensino Superior en el municipio de Salvador: el caso de la Universidad Federal de Bahia (UFBA)

\section{Elizabeth Reis Teixeira}

Professora doutora na Universidade Federal da Bahia, Salvador, Bahia, Brasil. ereist.teixeira@gmail.com ORCID - https://orcid.org/0000-0002-2546-1976

\section{Nanci Araújo Bento}

Professora doutora na Universidade Federal da Bahia, Salvador, Bahia, Brasil. nablibras@gmail.com

ORCID - https://orcid.org/0000-0002-0424-2547

Recebido em 20 de maio de 2019

Aprovado em 22 de julho de 2019

Publicado em 22 de outubro de 2019

\section{RESUMO}

Pretende-se, aqui, traçar um retrato das condições de acesso do estudante surdo às instituições públicas de ensino superior no município de Salvador, em especial na Universidade Federal da Bahia. Para tanto, serão examinadas as experiências vivenciadas no ensino secundário, que repercutem 0 sucesso/insucesso das políticas educacionais/linguísticas para esta população. A principal fonte de procedência do alunado surdo na UFBA - a AESOS (Associação Educacional Sons no Silêncio) será examinada. Com base nos pressupostos da pedagogia bilíngue (LODI; LACERDA, 2010; LODI, 2013) e com base nos estudos sobre políticas linguísticas (OLIVEIRA, 2016; BALDAUF JÚNIOR. 2004; BONACINA-PUGH, 2012), será empreendida uma análise documental dos principais projetos educacionais voltados para a promoção da educação superior do surdo. Os resultados apontam que o ingresso do estudante surdo, nos cursos de graduação da UFBA, tem-se dado através do sistema programado de reserva de vagas em projetos específicos voltados exclusivamente à promoção de sua formação superior: o Curso de Licenciatura em Letras Libras EAD, e o Curso de Pedagogia Bilíngue na modalidade online. No que diz respeito à Pós-Graduação, houve apenas três estudantes surdos antes da implantação, em 2017, do sistema de cotas para a Pós-graduação stricto sensu. Espera-se que nossos 
http://dx.doi.org/10.5902/1984686X38499

achados sobre a real situação de acesso da população surda ao nível superior nas instituições públicas locais, onde o ingresso através do processo classificatório ainda é dificultoso, excludente e replicador de desigualdades sociais e educacionais, venham a contribuir para o avanço das políticas públicas de acesso e permanência, para a produção de conhecimento na área da pedagogia bilíngue e para na formação de recursos humanos que influenciem as práticas educacionais das escolas para a população surda.

Palavras-chave: Educação de surdos; Perspectiva bilíngue; Políticas linguísticas; Ensino superior.

\section{ABSTRACT}

Based on bilingual pedagogy assumptions (LODI \& LACERDA, 2010; LODI, 2013) and on language policy studies (MÜLLER, 2016; BALDAUF JÚNIOR. 2014; BONACINA-PUGH, 2012), using documental analysis, a picture of access conditions of deaf students to federal higher education institutions in the municipal district of Salvador, in particular to the Federal University of Bahia is attempted. Considering high school experiences, which reverberate language/educational policies towards this population, an exam is attempted of the main origin of deaf students who enter UFBA: AESOS. Results point out that deaf student's access to UFBA's undergraduate courses has been possible due to special placement programs exclusively directed to promote higher education for the deaf: the Distance Education Portuguese Language-Brazilian Sign Language License Course and the Online Bilingual Pedagogy Course. As regards Graduate Courses, only three deaf students entered the university before the post-graduate quota system was implanted in 2017. As entrance examination protocols still present great difficulties, exclude and accentuate educational and social inequalities, our findings on the real access situation of deaf students to local public higher education institutions should contribute towards; advancing public education policies of access and continuity, producing knowledge in the area of Bilingual Pedagogy, and enhancing human resource training to upgrade educational practices in schools for the deaf.

Keywords: Deaf education; Bilingual perspective; Language policies; Higher education.

\section{RESUMEN}

Con base en los pressupuestos de la pedagogia bilingue (LODI y LACERDA, 2010; LODI, 2013) y los estudios sobre políticas linguísticas (MÜLLER, 2016; BALDAUF JÚNIOR. 2014; BONACINA-PUGH, 2012), a través de análisis documental, pretende-se trazar un cuadro de las condiciones de aceso del estudiante sordo a las instituiciones públicas de ensino superior en el municipio de Salvador, especialmente a Universidad Federal de Bahia, a partir de sus experiencias en la escuela secundaria, que reflejan en el êxito/fracaso de las políticas educacionales/linguísticas para esta populación, examinando la principal procedencia del alumnado sordo en UFBA - la AESOS. Los resultados apuntam que el ingreso de estudiantes sordos en los cursos de graduación de UFBA, se há dado a través del sistema programado de reserva de vagas en projetos dirigidos a la promoción de su formación superior: Curso de Licenciatura Letras Libras EAD, y Curso de Pedagogia Bilíngue online. En lo que respecta a Post-Grado, hubo apenas tres estudiantes sordos antes de la implantación, en 2017, del sistema de cotas. Espera-se que nuestros hallados 
sobre la real situación de aceso de sordos a el grado superior em las instituiciones públicas locales, dónde el proceso clasificatorio de ingreso és todavia dificultoso, excluyente y replicador de desigualdades sociales y educacionales, puedan contribuir para el avance de las políticas públicas de aceso y permanencia, de la producción de conocimientos en el área de pedagogia bilíngue, y en la formación de recursos humanos que influyan en las prácticas educacionales de las escuelas para sordos.

Palabras clave: Educación de sordos; Perspectiva bilingue; Políticas linguísticas; Enseñanza superior.

\section{Introdução}

O Panorama da Educação Superior no Brasil - Ensino Superior, de Esdras e Galasso (2017) - compilando os dados do Censo da Educação Superior realizado pelo INEP (Instituto de Estudos e Pesquisas Educacionais Anísio Teixeira), obtidos entre os anos de 2010 e 2015, mostram a dívida histórica acumulada no campo da Educação das pessoas surdas de nosso país: apenas $0,143 \%$ (se considerarmos a população de surdos como sendo de apenas 1,1 milhão de pessoas) estão em universidades. Deste montante, a maior parte dos surdos está em universidades ou faculdades privadas - na Bahia, $67,24 \%$, contra apenas $18,97 \%$ na rede pública federal, $10,34 \%$ na rede estadual e $3,45 \%$ na rede municipal.

Após o reconhecimento da Língua Brasileira de Sinais como meio de comunicação da comunidade surda brasileira (BRASIL, 2002) e a inserção da Libras como disciplina obrigatória nos cursos de formação de professores para o exercício do magistério e a obrigatoriedade da formação do docente para o ensino da Língua Brasileira de Sinais na educação infantil e nos anos iniciais do ensino fundamental (BRASIL,2005), diversas conquistas passam a ser asseguradas para a Comunidade Surda Brasileira. A primeira delas ocorre a partir da Universidade Federal de Santa Catarina, ao iniciar a oferta do Curso de Graduação de Licenciatura em Letras Libras em 2006 e, posteriormente, o Curso de Bacharelado Letras Libras em 2008, ambos com parcerias com diversas instituições educacionais de todo o Brasil, dentre elas a Universidade Federal da Bahia. Após a implementação do Curso Letras Libras, diferentes regiões do Brasil tiveram a oportunidade de formar professores surdos e ouvintes para o ensino da Língua Brasileira de Sinais nos diferentes níveis de ensino, e profissionais para a área de tradução e interpretação em diversos contextos sociais. 
http://dx.doi.org/10.5902/1984686X38499

Segundo Quadros (2014), entre os anos de 2000 e 2006, a população de pessoas surdas no Brasil com a faixa etária de 0 a 24 anos era de 776.884. Dessa população, $91,07 \%$ não faziam parte do sistema de ensino brasileiro. E, em relação ao ingresso de surdos no ensino superior, o índice era muito baixo: menos de 1\% da população, em comparação aos $17,8 \%$ de ouvintes. De acordo com a autora (2014, p.13), ocorreu um avanço significativo em relação ao ingresso das pessoas surdas no nível superior a partir da aprovação da Lei de Libras em 2002: houve "inserção dos surdos neste sistema de ensino no período de 2003 a 2005. Isto é, quando comparamos os dados de 2002 (344 alunos) com os de 2005 (2.428), tem-se um aumento de 705\% de surdos nas universidades brasileiras."

A implementação dos Cursos de Graduação de Licenciatura e Bacharelado em Letras Libras, voltados exclusivamente à educação do público surdo, representou, inegavelmente, o início das ações afirmativas em direção ao aceso e à formação dos primeiros surdos na universidade pública brasileira:

\begin{abstract}
Neste momento crucial, os primeiros surdos se formaram na universidade pública e houve o reconhecimento da aprendizagem dos surdos bem como a forma da escrita como segunda língua. Uma das consequências desse processo de formação é a presença de surdos atores da educação de surdos, ou seja, os primeiros surdos com formação para atender e decidir a educação dos próprios surdos. Esses surdos devidamente qualificados passam a integrar o movimento dos surdos e, a partir disso, surgem as propostas sobre o que eles querem para a Educação de Surdos juntamente aos órgãos que definem as políticas de educação no país (QUADROS, 2014, p.33)
\end{abstract}

Em momento posterior, em 17 de novembro de 2011, o Governo Federal lançava o Plano Nacional dos Direitos da Pessoa com Deficiência - Viver sem Limite, por meio do Decreto 7.612, em respeito ao compromisso do Brasil com as prerrogativas da Convenção da ONU sobre os Direitos das Pessoas com Deficiência.

O Plano Viver sem Limite foi elaborado com a participação de mais de 15 ministérios e do CONADE (Conselho Nacional dos Direitos da Pessoa com Deficiência), representando a sociedade civil e envolveu todos os entes federados. Representou a articulação de políticas governamentais de acesso à educação, inclusão social, atenção à saúde e acessibilidade, com a previsão de um investimento total no valor de R \$ 7,6 bilhões até 2014 .

Com base no princípio de que o acesso à educação é direito de todos, sem discriminação, em igualdade de oportunidades, o plano Viver sem Limite se propunha a investir em recursos e serviços de apoio à educação básica, envolvendo: a implantação de Salas de Recursos Multifuncionais, a promoção de acessibilidade nas escolas, a formação 
http://dx.doi.org/10.5902/1984686X38499

de professores para o Atendimento Educacional Especializado, a aquisição de ônibus escolares acessíveis e a ampliação do Programa BPC na Escola (Benefício de Prestação Continuada da Assistência Social). Em termos de educação profissional, garantia prioridade às pessoas com deficiência na matrícula dos cursos do PRONATEC (Programa Nacional de Acesso ao Ensino Técnico e Emprego). Nas IFES (Instituições Federais de Ensino Superior), havia a previsão de instalação de núcleos de acessibilidade e a oferta de cursos de Letras/Libras e de formação em Pedagogia na perspectiva bilíngue (Libras/ Língua Portuguesa).

De forma paralela às ações afirmativas iniciadas pela UFSC na década anterior, e com o intuito de diminuir a dívida histórica em relação à educação de surdos no país, o INES (Instituto Nacional de Educação de Surdos), em parceria com o MEC, encabeçou a proposta de oferta do Curso de Pedagogia Bilíngue a distância. Dada a escassez de pessoal qualificado no campo da Educação Bilíngue para Surdos, a opção de formação através do trabalho coletivo, em um processo de rede de formação, pareceu ser uma solução viável. Esta rede foi composta, inicialmente, por 10 instituições públicas de ensino superior. Os cinco critérios utilizados pelo MEC/INES para a escolha dos polos que compunham a rede foram: a falta de professores capacitados em cada região para atender a demanda segundo a quantidade de alunos surdos matriculados na Educação Infantil e primeiro segmento do Ensino Fundamental (de acordo com o Censo do IBGE de 2010); experiência da instituição em educação a distância na modalidade "graduação em situação de rede com outras instituições, de forma semelhante ao projeto Letras-Libras do convênio MEC-UFSC; capacitação do coordenador do polo com ensino e pesquisa no campo da Educação de Surdos; infraestrutura da instituição para o acolhimento de um polo; e facilidade de acesso dos estudantes à cidade onde se localizaria o polo local.

O INES, portanto, em conformidade às ações educacionais que objetivavam a expansão do Ensino Superior em favor da inclusão e acessibilidade preconizadas no Viver sem Limite, iniciou, em 2013, um projeto para a implementação do Curso de Pedagogia Bilíngue a distância. O curso, contudo, só iniciou suas atividades em março de 2018, contando, finalmente, com a participação de 13 polos nas cinco regiões do país, distribuídos da seguinte forma: região norte - Universidade Federal do Amazonas (UFAM), Universidade do Estado do Pará (UEPA); região nordeste - Universidade Federal do Ceará (UFC), Universidade Federal da Paraíba (UFPB) e Universidade Federal da Bahia (UFBA); região centro-oeste - Universidade Federal da Grande Dourados (UFGD), Instituto Federal 
http://dx.doi.org/10.5902/1984686X38499

de Goiás (IFG); região sudeste - Instituto Nacional de Educação de Surdos (INES - sede), Universidade Federal de São Paulo (UNIFESP), Universidade Federal de Lavras (UFLA); região sul - Universidade Federal do Paraná (UFPR), Universidade Federal do Rio Grande do Sul (UFRGS). Está previsto, no projeto do curso, o oferecimento de 390 vagas totais anuais, sendo 30 para o polo INES e 30 para cada um dos demais polos, perfazendo um total de 1950 vagas até 2023, sendo metade delas reservadas a alunos surdos, conforme Política Institucional do INES.

Como a garantia da acessibilidade à educação superior é uma temática de abordagem relativamente recente, coloca-se como de extrema relevância pesquisar sobre 0 desenvolvimento e a concretização das leis para saber se, de fato, as pessoas com necessidades educacionais especiais estão tendo acesso ao conhecimento, o quanto está se avançando nesse contexto, e o que ainda precisa ser melhorado.

Para entender como tem se dado o acesso do estudante surdo às instituições públicas de ensino superior no município de Salvador, em especial à Universidade Federal da Bahia, é importante verificar a situação do ensino secundário e as políticas educacionais/linguísticas para esta população vigentes no município.

Para tanto, examinaremos documentos dos cursos Letras Libras e Pedagogia Bilíngue, ambos com polo de ensino na UFBA, voltados para a comunidade surda, e as práticas didáticas desenvolvidas na Associação Educacional Sons no Silêncio - a AESOS, escola que tem formado o alunado surdo que tem ingressado na instituição.

\section{Marcos Teóricos: a Educação Bilíngue e as Políticas Linguísticas}

O uso de uma língua, diferente da língua (oral) usada em seu país, faz do surdo um indivíduo com uma maneira diferente de pensar e ver o mundo. O surdo é, essencialmente, um indivíduo bicultural, pois, além de ter sua cultura própria demarcada pelo uso da língua de sinais, interage socialmente com os indivíduos da comunidade ouvinte em que está inserido. Existe consenso em relação ao fato de que o desenvolvimento da linguagem depende do acesso à comunicação frequente e consistente, e da interação da criança com um meio linguístico adequado - quer seja ele falado ou sinalizado.

O Bilinguismo, como proposta para a educação de surdos, surgiu entre as década de 80 e 90 (MAYER e AKAMATSU, 1999; HERMANS, KNOORS, ORMEL e VERHOEVEN, 2008). Esta linha teórica defende que o aprendizado da Língua sinalizada deve preceder 0 
http://dx.doi.org/10.5902/1984686X38499

da Língua oral, utilizada na comunidade na qual o surdo está inserido. Assim, do ponto de vista linguístico, em consonância ao Decreto Federal ํㅜ 5626, o surdo brasileiro deve ter a Língua Brasileira de Sinais como o seu meio natural de comunicação - sua primeira língua (L1), e utilizá-la no seu aprendizado dos primeiros conteúdos escolares (no ensino básico). Contudo, deve, também, aprender a modalidade escrita da língua portuguesa como segunda língua (sua L2).

Na significação dada à educação bilíngue para surdos pelo Decreto, observase que a Libras assume papel central, fato que demanda "mecanismos alternativos para a avaliação de conhecimentos expressos em Libras, desde que devidamente registrados em vídeo ou em outros meios eletrônicos e tecnológicos" (Artigo $14, \S 1^{\circ}$, Inciso VII). A linguagem escrita da língua portuguesa, compreendida e trabalhada nos espaços escolares como segunda língua, deve ser ensinada também como conteúdo de complementação curricular (Artigo 15), requerendo mecanismos de avaliação. (LODI, 2013, p.55)

Apesar de não chegar (em muitos casos, a depender das circunstâncias aquisicionais) a adquirir e utilizar a língua oral, o surdo conta com integridade viso-sensorial e intelectual para fazer uso da grafia da língua da comunidade em que está, fisicamente, inserido. Nos dias de hoje, o domínio da leitura e da escrita é condição essencial para o convívio com as mais diversas práticas sociais que permeiam as rotinas dos indivíduos em sociedades urbanas, tendo em vista ser a escrita uma tecnologia de acesso a diferentes fontes de informação, que contribui para o desenvolvimento educacional e desempenho social daqueles que dela fazem uso.

$\mathrm{Na}$ pesquisa "A Situação Linguística da Criança Surda Frente ao Desafio do Letramento: Problema de Aquisição da Linguagem", realizada de 2007 a 2010, na UFBA, foi feito um levantamento da situação linguística do alunado da terceira e quarta séries em escolas para surdos na cidade de Salvador, a fim de traçar um diagnóstico de suas condições de letramento. Detectou-se que existem dificuldades de compreensão da Libras por parte dos alunos surdos, devido a sua aquisição tardia da linguagem (em geral, a partir dos 5 anos - quando chegam à escola; devido a não receberem de seus pais ouvintes o input necessário a um desenvolvimento natural de suas habilidades linguísticas; e pelo fato de, na escola, nem todos os professores terem o domínio da Libras, utilizando-a apenas como forma de língua franca. Constatou-se defasagem entre série escolar e idade cronológica esperada. A menor idade entre os sujeitos testados foi de 11 anos e a máxima foi de 18 anos no CAS/BA e de 8 e 15 anos na AESOS. A melhor relação idade/série foi a 
http://dx.doi.org/10.5902/1984686X38499

de 11 anos/3 $3^{\mathrm{a}}$ série, a menos adequada sendo a de 18 anos/4 ${ }^{\mathrm{a}}$ série no CAS/BA e de 8 anos/3aㅗ série e 15 anos/4를 série na AESOS. (TEIXEIRA; MARINHO, 2012)

Estes resultados evidenciaram que as escolas locais da rede pública de ensino, e mesmo as especializadas na educação de surdos, mostravam baixo grau de eficiência na tentativa de propiciar letramento satisfatório para esta população específica. $O$ ensino de língua portuguesa para surdos, nestes estabelecimentos, também carecia de melhoria, pois não os preparava, da forma mais adequada, para enfrentar os processos seletivos nas instituições públicas de ensino superior, a não ser quando garantidos por sistemas de reserva de vagas, conforme o praticado nos cursos Letras Libras, em 2006 e 2008, e no Curso Pedagogia Bilíngue, em 2018 e 2019; e/ou por sistema cotas, amparado na Lei no 13.409, de 28 de dezembro de 2016, que altera a Lei oㅜ 12.711, de 29 de agosto de 2012, para dispor sobre a reserva de vagas para pessoas com deficiência nos cursos técnicos de nível médio e superior das instituições federais de ensino.

É fundamental que a escolarização do surdo, como sujeito de aprendizagem, se realize em um ambiente propício, na perspectiva da educação bilíngue, a partir do contato com um sistema linguístico sinalizado desde cedo, para que possa, com maior facilidade e naturalidade, desenvolver sua identidade linguística.

O direito a ser educado em uma língua não majoritária é apenas o primeiro passo em direção à criação de uma política linguística que ofereça condições para que os surdos possam desenvolver suas potencialidades referentes à aquisição de uma primeira língua, à identidade com seus pares, à participação no debate linguístico e educacional, à vida comunitária e ao desenvolvimento de processos específicos de aprendizagem e produção cultural construído histórica e socialmente pelas comunidades surdas.

Promover projetos de aquisição de primeira língua deve ser um primeiro e importantíssimo compromisso das instituições escolares. Além dos conteúdos curriculares da educação formal, cabe, ao espaço escolar, também a educação linguística. A instituição, portanto, passa a ter um papel linguístico duplo: precisa fornecer um contexto de aquisição de língua natural (primeira língua) e oferecer o ensino da língua oral majoritária como segunda língua (na modalidade escrita). As instituições de ensino superior, por sua vez, devem carregar o compromisso de formar professores que reflitam sobre essa questão e estejam aptos a promoverem ações neste sentido.

A partir da promulgação do Decreto $\mathrm{n} .-7.387$ (BRASIL, 2010), que institui o Inventário Nacional da Diversidade Linguística, a fim de inventariar as línguas brasileiras: 
http://dx.doi.org/10.5902/1984686X38499

Foi adotada pelo Instituto do Patrimônio Histórico e Artístico Nacional;/Ministério da Cultura a categorização das línguas minoritárias brasileiras que incluiu: línguas indígenas, variedades regionais da língua portuguesa, línguas de imigração, línguas de comunidade afro-brasileiras, língua brasileira de sinais e línguas crioulas. Como um dos resultados desse inventário, houve, novamente, o reconhecimento da Libras como língua nacional $e$, consequentemente, 0 direito dos brasileiros oriundos das comunidades surdas à preservação de sua língua - Libras - e cultura, do que decorre, novamente, o direito de terem escolas específicas e formação de educadores graduados com currículo que atenda e respeite as diferenças linguísticas e culturais dessas pessoas. (MEC/SECADI,2014, p.5)

Assim, a Educação de Surdos deixa de estar vinculada às ações na área da Educação Especial, e às políticas públicas de atendimento educacional especializado do alunado com deficiências. "Considerado como parte de uma comunidade linguístico cultural, o estudante surdo requer outro espaço do MEC para implementar uma educação bilíngue regular que atenda as distintas possibilidades de ser surdo". (MEC/SECADI,2014, p.7)

A política linguística instaurada por meio do Decreto $n .^{\circ}$ 5.626/2005, em regulamentação à Lei n.. 10.436/2002, na verdade, traz, como consequência, diversos desdobramentos em termos de planejamento linguístico, com uma série de ações de implantação, implementação e difusão da Libras no Brasil, e de adequação da Língua Portuguesa - como L2 - para o acesso das pessoas surdas à educação, incluindo, aí, os exames institucionais que envolvem avaliações de seleção de candidatos e estudantes (provas de seleção de ingresso no ensino médio e superior e outras) e avaliações em sala de aula (tais como testes e provas).

O Relatório do Grupo de Trabalho do MEC/SECADI (2014) apresenta recomendações para a elaboração e execução de avaliações tanto em Libras e de Libras como primeira língua, quanto de língua portuguesa e em língua portuguesa como segunda língua. A avaliação de exames institucionais, como o ENEM (Exame Nacional de Ensino Médio), vestibulares e os concursos públicos, entre outros, deve seguir as recomendações do CONADE (Conselho Nacional dos Direitos da Pessoa com Deficiência), e da Comissão Assessora de Especialistas em Educação Especial e Atendimento Diferenciado em Exames e Avaliações da Educação Básica23 do INEP (Instituto Nacional de Estudos e Pesquisas Educacionais Anísio Teixeira).

Conforme apontam Martins, Leite e Lacerda (2015), com base nos dados do INEP, apesar do aumento de matrículas de pessoas com deficiência no Ensino Superior nos últimos dez anos (de 2000 a 2010), sobretudo após a criação do programa Incluir, ainda é inexpressivo o número de estudantes surdos no Ensino Superior. De acordo com os dados 
http://dx.doi.org/10.5902/1984686X38499

analisados pelas autoras referentes às condições de acessibilidade, os estudantes com deficiência auditiva (aí incluída a surdez) representaram $24,34 \%$ do total de matrículas de PCDs no ano 2011:

[...] o número total de ingressantes no ano de 2011 foi de 2.346 .695 (em cursos presenciais e a distância), sendo 7.992 de $\mathrm{PcD}$, e destes 495 eram estudantes com surdez e 1.465 com deficiência auditiva. (MARTINS; LACERDA, 2015, p.93)

O estudante surdo que chega ao fim da trajetória escolar na Educação Básica precisará ainda submeter-se a um instrumento avaliativo para ingresso na universidade, o vestibular ou o Enem.

A média nacional dos estudantes é 478,11 pontos e a situação torna-se mais crítica quando o foco se dirige para os estudantes surdos, cuja média é de 360,82 pontos. Esse resultado pode indicar que a educação ofertada a este público não tem alcançado a qualidade esperada, ou seja, essa população não tem sido contemplada com uma educação que favoreça sua aprendizagem dentro dos parâmetros previstos para este nível de ensino. (MARTINS; LACERDA, 2015, p.98)

Mediante as condições explicitadas, poucos são aqueles que conseguem, com uso da nota obtida no Enem, ingressar em cursos superiores. [...] Cabe indagar se os problemas estão somente na preparação desses estudantes durante o Ensino Médio ou se a própria forma de apresentação do exame compromete o seu desempenho. Há indicativos recentes de que, nos processos seletivos para ingresso e permanência nos cursos oferecidos pelas instituições de Ensino Superior e de educação profissional e tecnológica, públicas e privadas, se deve adotar a tradução completa do edital e de suas retificações em Libras (Brasil, 2015). Com a adoção dessa medida, o número de interessados e aprovados nos exames poderá crescer, já que as condições de acessibilidade serão mais favoráveis. Contudo permanece a indagação sobre a qualidade da educação ofertada a esses estudantes, e os modos como as avaliações de larga escala podem ser efetivamente sensíveis a essa qualidade. (MARTINS; LACERDA, 2015, p.98)

Apenas a partir de 2017, o Instituto Nacional de Estudos e Pesquisas Educacionais Anísio Teixeira (INEP), pela primeira vez, passou a oferecer vídeo-provas do Enem traduzidas em Língua Brasileira de Sinais (Libras) para os candidatos surdos. As provas foram traduzidas em parceria com a Universidade Federal de Santa Catarina (UFSC), que já oferecia a versão em Libras em seu vestibular. No ato da inscrição, o candidato com surdez poderia optar por três diferentes recursos: vídeo-prova traduzida em Libras; auxílio de tradutor-intérprete de Libras, para a tradução de orientações gerais e esclarecimento de dúvidas específicas da língua portuguesa escrita; recurso de leitura labial, em que um profissional usa técnicas de interpretação e de leitura dos movimentos labiais. 
http://dx.doi.org/10.5902/1984686X38499

Esta medida, contudo, ao que parece, até o momento, infelizmente, ainda não conseguiu contribuir para o acesso de estudantes surdos aos cursos de graduação da UFBA.

\section{Metodologia}

Com base nos pressupostos da pedagogia bilíngue (LODI \& LACERDA, 2010; LODI, 2013) e com base no estudos sobre políticas linguísticas (OLIVEIRA, 2016), e através de análise documental, pretende-se traçar um retrato das condições de acesso do estudante surdo às instituições públicas de ensino superior no município de Salvador, em especial na Universidade Federal da Bahia, a partir de suas experiências no ensino secundário, que repercutem o sucesso/insucesso das políticas educacionais/linguísticas para esta população no município.

A fim de entendermos a razão pela qual os surdos tem tido dificuldade em acessar o sistema público de educação superior, tentaremos examinar as práticas didáticas que tem preparado os alunos para se apresentarem nos processos seletivos de acesso ao ensino superior, todos estes conduzidos em língua portuguesa, em especial o que tem sido desenvolvido na Associação Educacional Sons no Silêncio - a AESOS, principal fonte de procedência do alunado surdo hoje frequentando a UFBA através de convênio.

Para tanto, estamos utilizando os seguintes documentos:

- Relatório do Curso Letras Libras - Polo UFBA - Turma 2006-2010;

- Relatório do Curso Letras Libras - Polo UFBA - Turma 2008-2012;

- Relatório do Curso Pedagogia Bilíngue - Polo UFBA - Turmas 2018 e 2019;

- Retrospectiva Especial - UFBA 70 Anos;

- UFBA - Relatório llustrado 2014-2017;

- UFBA em números - Ano base 2017;

- Relatório interno do Núcleo de Apoio à Pessoa com Necessidades Especiais - NAPE/PROAE/UFBA - 2018;

- Relatório interno do Núcleo de Apoio à Pessoa com Necessidades Especiais - NAPE/PROAE/UFBA - 2019/1;

- Projeto Político Pedagógico da Associação Educacional Sons no Silêncio (AESOS) e do Centro Educacional Sons no Silêncio (CESS). 
http://dx.doi.org/10.5902/1984686X38499

\section{O estudante surdo em Instituições Federais de Ensino Superior no município de Salvador: o caso da Universidade Federal da Bahia (UFBA)}

Apesar do total de matrículas de pessoas surdas no sistema de ensino brasileiro na última década ter aumentado, a análise de dados estatísticos revela, ainda, um cenário preocupante no que diz respeito ao ingresso de alunos surdos na região nordeste em Instituições de Ensino Superior (IES), conforme os dados compilados por Esdras e Galasso (2017) acima apresentados.

$\mathrm{Na}$ Universidade Federal da Bahia, a situação não é diferente. O ingresso do estudante surdo, nos cursos de graduação da UFBA, tem-se dado, basicamente, através do sistema programado de reserva de vagas em projetos específicos voltados exclusivamente à promoção de sua formação superior: o Curso de Licenciatura em Letras Libras EAD, e o Curso de Pedagogia Bilíngue na modalidade online. No que diz respeito à Pós-Graduação, houve apenas três estudantes surdos antes da implantação, em 2017, do sistema de cotas para a Pós-graduação stricto sensu: dois no Curso de Mestrado em Educação e um no Programa de Pós-Graduação em Letras e Linguística, do Instituto de Letras da UFBA - todos eles contando com o incentivo e empenho dos professores orientadores, pesquisadores nas áreas de Estudos Surdos e/ou Estudos Linguísticos da Língua de Sinais.

\section{O Curso Letras - Libras: Polo UFBA}

Em termos de atividades de Ensino, a Universidade Federal da Bahia abrigou, de outubro de 2006 a março de 2012, o polo do Curso de Licenciatura em Letras com habilitação em Língua Brasileira de Sinais - Libras, através de convênio celebrado entre o MEC, a Universidade Federal da Bahia e a Universidade Federal de Santa Catarina. Em 2010, graduou-se a primeira turma de licenciados em Letras - Libras e, em 2012, a segunda turma de Licenciatura e de Bacharelado em Tradução e Interpretação de Libras - Língua Portuguesa. Com processo seletivo próprio, o curso garantiu reserva de metade das 30 vagas de cada turma para estudantes surdos.

O Curso de Graduação de Licenciatura em Letras Libras EAD teve, no caso da Licenciatura, o objetivo de formar professores para atuar no ensino da de Língua Brasileira de Sinais como primeira (L1) e segunda língua (L2). O Curso de Bacharelado, visava a formação de tradutores e intérpretes de Língua Brasileira de Sinais/Língua Portuguesa. 
http://dx.doi.org/10.5902/1984686X38499

Este, portanto, foi o primeiro movimento em relação às ações afirmativas e de promoção de acessibilidade para o surdo na UFBA. Tanto na turma de 2006 como na de 2008, matricularam-se e graduaram-se 15 alunos surdos, perfazendo um total de 30 alunos surdos graduados.

À medida que existiam, na primeira turma iniciada em 2006, apenas dois polos do Curso na região Nordeste (Bahia e Fortaleza), o Polo UFBA teve grande relevância não apenas em nível local, uma vez que recebeu alunos dos estados de Alagoas, Pernambuco e Paraíba, conforme mostrado abaixo:

Gráfico 1 - Distribuição do alunado do polo UFBA por estado - 2006

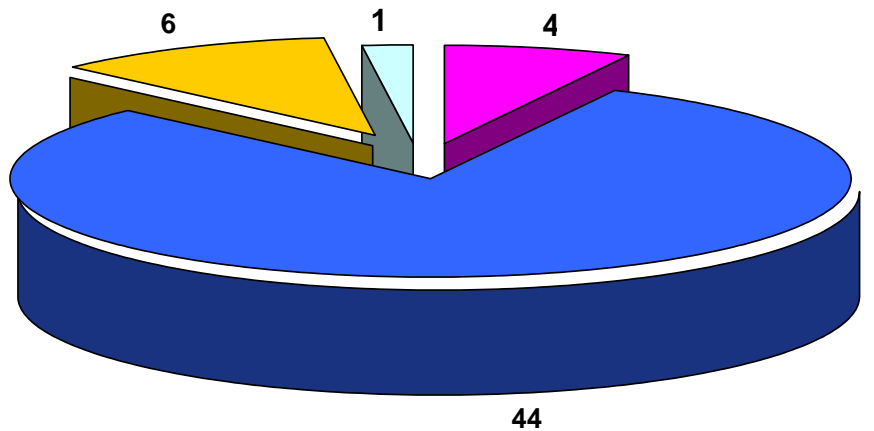

$\square$ ALAGOAS $\square$ BAHIA $\square$ PERNANBUCO $\square$ PARAÍBA

Fonte: Polo UFBA - Curso Letras Libras (2010).

Na turma de 2008, embora tenham sido acrescidos mais dois polos na região Nordeste (UFPE e CEFET/RN), o Polo UFBA continuou recebendo alunos dos estados de Alagoas, Pernambuco e Sergipe. 
http://dx.doi.org/10.5902/1984686X38499

Gráfico 2 - Distribuição do alunado do Polo UFBA por estado - 2008

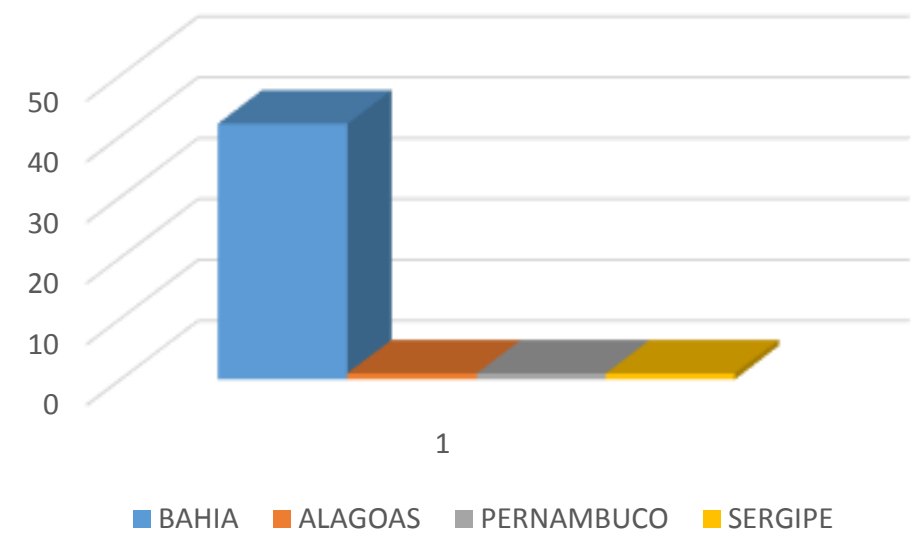

Fonte: Polo UFBA - Curso Letras Libras (2012).

\title{
O Curso Pedagogia Bilíngue - Polo UFBA
}

A proposta do Curso Pedagogia Bilíngue na modalidade online, concebida pelo Instituto Nacional de Educação de Surdos (INES), com a perspectiva bilíngue e intercultural, é desenvolvida por meio de um Ambiente Virtual de Aprendizagem (AVA) e de atividades presenciais obrigatórias. De acordo com seu Projeto Pedagógico:

\begin{abstract}
A linguagem que possibilita a mediação entre o ambiente online e o contexto presencial é totalmente digitalizada através de hipermídias, utilizando espaços de comunicação assíncronos (fóruns, blogs, jogos, glossários etc.) e síncronos (chats, vídeo conferência, mapas mentais), onde o estudante tem contato com o conteúdo do curso e pode refletir sobre diferentes perspectivas dos conhecimentos necessários para a sua aprendizagem. (INES, 2015, p.16)
\end{abstract}

O Curso objetiva formar professores e gestores educacionais, surdos e ouvintes, para atuar na área da docência na Educação Infantil e nos anos iniciais do Ensino Fundamental, em consonância ao artigo 5o do Decreto 5626/2005. Para o ingresso ao Curso de Pedagogia Bilíngue na modalidade online, o Instituto Nacional de Educação de Surdos utilizou a maior nota obtida em uma das três últimas edições do Exame Nacional do Ensino Médio (ENEM), anos 2016,2017 e 2018. São reservadas 50\% das vagas para estudantes que tenham cursado integralmente o ensino médio em escolas públicas, em observância às Lei № 12.711, de 29 de agosto de 2012 (a Lei de Cotas) e a Lei № 13.409, de 28 de dezembro de 2016.

O processo de negociação do INES junto à Reitoria da UFBA teve início, formalmente, a partir de julho de 2013, com a manifestação favorável da Reitoria. Embora o primeiro documento entre UFBA e INES tenha sido assinado em 13 de abril de 2015, seguido de outro 
em 27 de junho de 2016, o curso só começou, efetivamente, em março de 2018. Nesta primeira turma foram matriculados 30 alunos: 15 ouvintes e 15 surdos, o mesmo ocorrendo com a segunda turma iniciada em 2019, perfazendo, no momento, um total de 30 alunos surdos matriculados.

Assim como ocorreu no Letras Libras, o Polo UFBA continua atendendo ao alunado de todo o estado da Bahia (estado que possui uma área territorial de $564.733 \mathrm{~km}^{2}$ e faz divisa com oito estados) bem como de outros estados, a exemplo de Petrolina em Pernambuco, conforme o gráfico abaixo.

Gráfico 3 - Cidades de origem dos estudantes do pedagogia bilíngue - Polo UFBA - 2018 e 2019

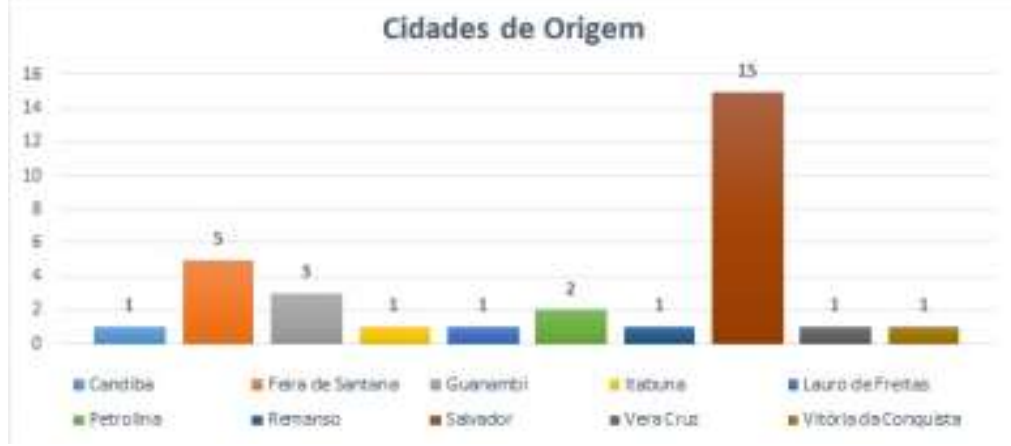

Fonte: Polo UFBA - Curso Letras Libras (2012).

Considerando a procedência do corpo discente, constata-se que o alunado surdo é, predominantemente, procedente da escola AESOS - escola de surdos localizada no município de Salvador.

Gráfico 4 - Procedência escolar dos estudantes do Pedagogia Bilíngue- Polo UFBA - 2018 e 2019

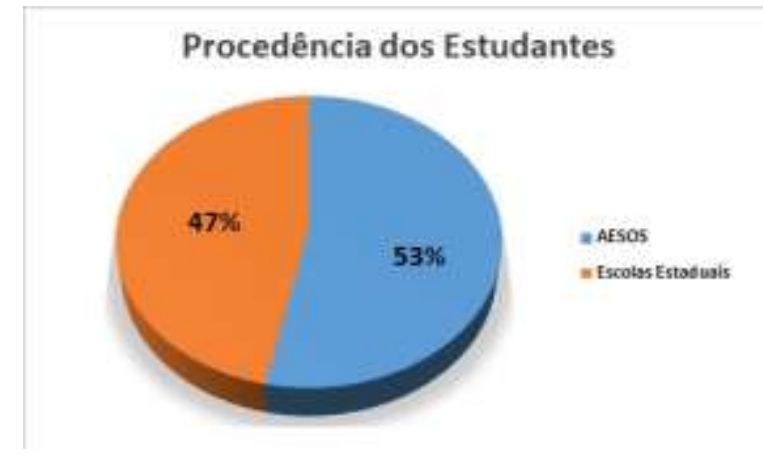

Fonte: Polo UFBA - Curso Pedagogia Bilíngue (2019). 
http://dx.doi.org/10.5902/1984686X38499

\section{Pós-Graduação}

No que diz respeito à Pós-Graduação, apenas três estudantes surdos haviam conseguido entrar em cursos na instituição até 2018. Na Faculdade de Educação da UFBA (FACED), em 2009, duas estudantes surdas obtiveram o grau de Mestre, com Dissertações que versaram sobre: "A Prioridade dos Docentes Surdos para Ensinar a Disciplina Língua Brasileira de Sinais (Libras) nas Instituições de Ensino Superior após o Decreto 5.626/2005" (REBOUÇAS, 2090, e "Olhares sobre si: a busca pelo fortalecimento das identidades surdas" (ROSA, 2009).

No Programa de Pós-Graduação em Letras e Linguística, do Instituto de Letras da UFBA, um estudante surdo foi aprovado para o mestrado com o projeto - Aquisição da Língua Brasileira de Sinais (LIBRAS) como segunda língua por crianças ouvintes: um estudo de caso, mas, infelizmente, não chegou a concluir o trabalho final.

Com o sistema de cotas aprovado pela Resolução 01/2017, do Conselho Acadêmico de Ensino, que "institui normas para procedimentos, editais e reservas de vagas para processos seletivos da Pós-Graduação stricto sensu da UFBA", dois novos estudantes surdos foram selecionados para os cursos de Mestrado em Educação e Mestrado em Mecatrônica em 2019/1.

Conforme comprovam os dados acima apresentados, o ingresso de estudantes surdos nos cursos de graduação da UFBA se deu exclusivamente através da política de reserva de vagas de projetos especiais voltados para atender às demandas de inclusão de surdos na educação superior, como ocorreu no Curso de Licenciatura em Letras Libras EAD - em que matricularam-se e graduaram-se um total de 30 alunos surdos, e no curso Pedagogia Bilíngue na modalidade online, em que foram matriculados, até o momento, um total de 30 alunos surdos. Em relação à Pós-Graduação, o número de ingressos também foi bastante limitado.

Estes números de ingresso de estudantes surdos na UFBA são realmente muito tímidos se comparados ao número total de matrículas em cursos de Graduação e Pós-graduação stricto sensu na UFBA entre 2008 e 2018, conforme atestam os dados abaixo: 
http://dx.doi.org/10.5902/1984686X38499

Quadro 1 - Número total de matrículas em cursos de graduação e pós-graduação stricto sensu na UFBA entre 2008 e 2018

\begin{tabular}{|c|c|c|}
\hline Ano & Graduação & $\begin{array}{c}\text { Pós- } \\
\text { graduação } \\
\text { stricto sensu }\end{array}$ \\
\hline 2008 & 24.367 & 3.116 \\
\hline 2010 & 28.562 & 3.801 \\
\hline 2012 & 32.241 & 4.704 \\
\hline 2014 & 33.767 & 5.141 \\
\hline 2015 & 33.804 & 5.978 \\
\hline 2016 & 34.371 & 6.184 \\
\hline 2017 & 37.985 & 7.045 \\
\hline
\end{tabular}

Fonte: Universidade Federal Da Bahia, (2016); Universidade Federal Da Bahia (2018a); Universidade Federal Da Bahia; (2018b).

A este respeito, são bastante reveladores, também, os dados relativos ao atendimento do Núcleo de Apoio à Pessoa com Necessidades Especiais - NAPE/PROAE/UFBA em relação às estatísticas de estudantes que recorreram ao apoio do Núcleo até 2018 e em 2019/1. De acordo com estes dados, foram identificados estudantes ingressantes em 2019/1 com Deficiência Auditiva nos cursos de Graduação em Letras (1), Mestrado em Biologia (1) e Mestrado em Computação (1).

Em 2018, conforme demonstrado no Gráfico 5 abaixo, $54 \%$ dos alunos que demandavam apoio do NAPE possuíam deficiência visual, 28\% deficiência físico-motora e $8 \%$ deficiência intelectual, enquanto apenas $2 \%$ tinham Superdotação/Altas habilidades. Não existem registros de demanda de atendimento para surdos em 2018, assim como nos anos anteriores. Em 2019/1, contudo, conforme demonstrado no Gráfico 6 abaixo, surgem demandas tanto de apoio para surdos (2) bem como para deficientes auditivos (2): no primeiro caso, intérpretes de Libras/Língua Portuguesa e, no segundo caso, tecnologias para amplificação de voz. 
http://dx.doi.org/10.5902/1984686X38499

Gráfico 5 - Quantitativo de alunos atendidos pelo NAPE por deficiência - 2018

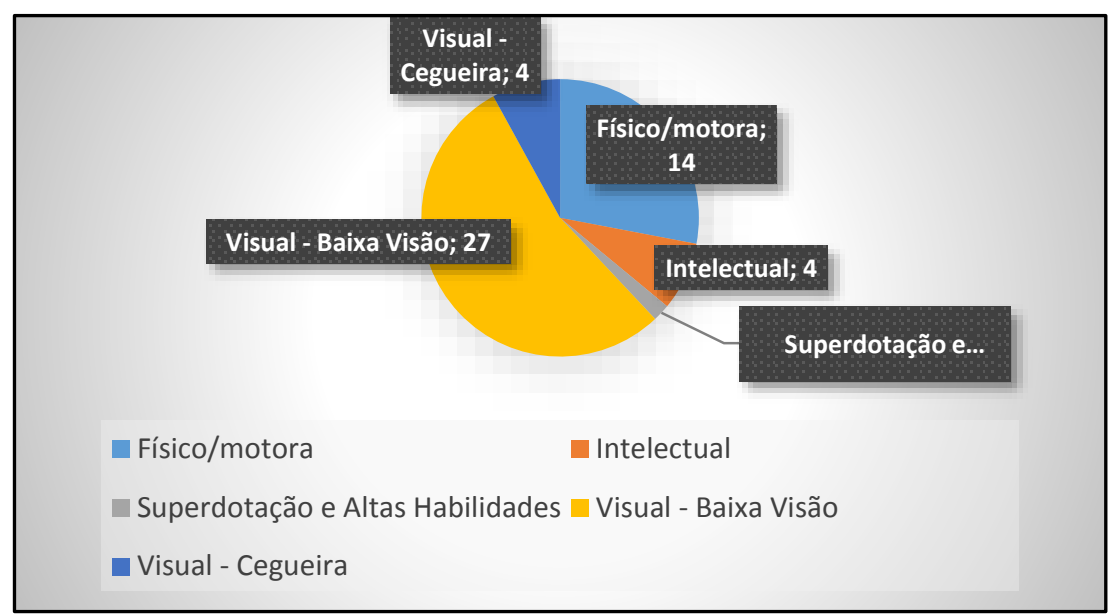

Fonte: NAPE/UFBA (2018).

Gráfico 6 - Quantitativo de alunos atendidos pelo NAPE/UFBA em 2019/1

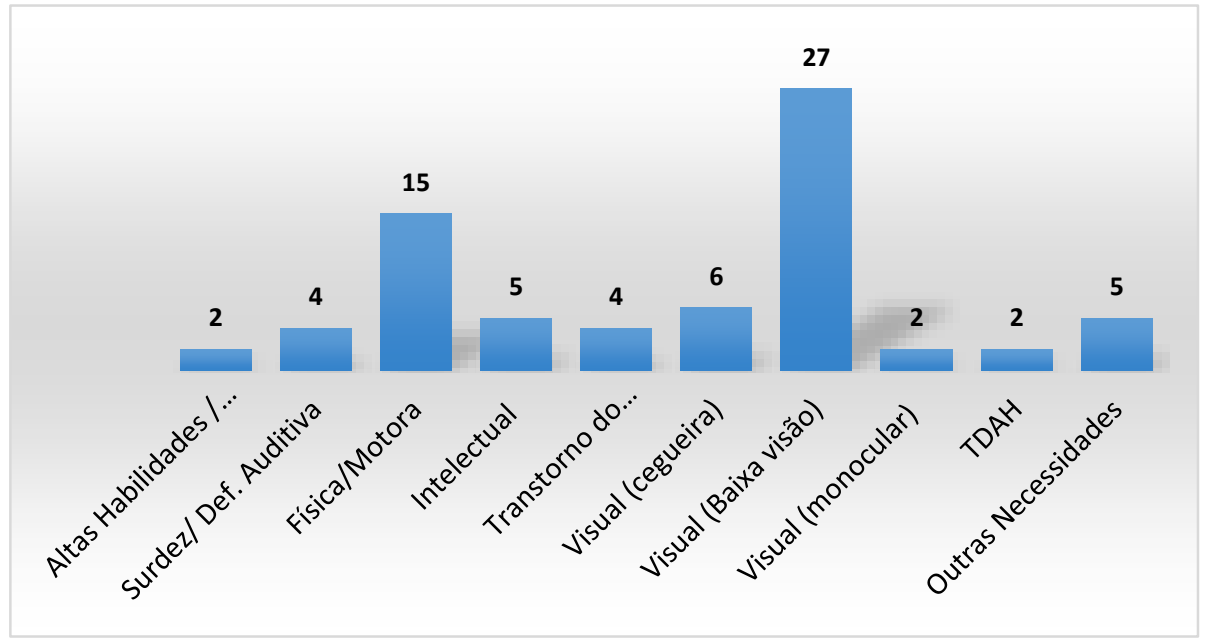

Fonte: NAPE/UFBA (2019/1).

A fim de entendermos a razão pela qual os surdos tem tido dificuldade em acessar o sistema público de educação superior, tentaremos examinar as práticas didáticas que tem preparado os alunos para se apresentarem nos processos seletivos de acesso ao ensino superior, todos estes conduzidos em língua portuguesa, em especial o que tem sido desenvolvido na Associação Educacional Sons no Silêncio - a AESOS, principal fonte de procedência do alunado surdo hoje frequentando a UFBA através de convênio. 
http://dx.doi.org/10.5902/1984686X38499

\section{Associação Educacional Sons no Silêncio (AESOS) e o Centro Educacional Sons no Silêncio (CESS)}

Fruto do movimento Sociedade Civil da Comunidade Surda soteropolitana, três mães de surdos, insatisfeitas com o desempenho linguístico de seus filhos estudantes de escolas inclusivas, fundaram, em 2000, a Associação Educacional Sons no Silêncio. A AESOS é, atualmente, a única instituição de espaço civil especializada na área da educação para pessoas surdas na Cidade de Salvador que atende, na perspectiva bilíngue, alunos surdos no ensino básico, desde o ensino fundamental, ensino médio e educação de Jovens e Adultos.

No período entre 2000 e 2002, quando a AESOS não desenvolvia ainda atividades de cunho educacional formal, as ações desenvolvidas envolviam Apoio Pedagógico, qualificação profissional e assistência social para surdos e familiares de pessoas surdas. Em 2003, a AESOS cria o Centro Educacional Sons no Silêncio (CESS), com ensino gratuito, em convênio de cooperação técnica com a Secretaria de Educação do Estado da Bahia (SEC). Surge, assim, a escola especializada, prioritariamente para estudantes surdos, deficientes auditivos e filhos ouvintes de pais surdos (CODA's) ${ }^{1}$. Em 2004, amplia o convênio para a Secretaria Municipal da Bahia (SMED).

Em 2009, o CESS implanta a Educação de Jovens e Adultos (EJA), na modalidade Tempo Formativo, pela necessidade de garantir o acesso à permanência e continuidade nos estudos dos jovens surdos e adultos surdos inseridos no mercado de trabalho. Em 2011, ocorre a implementação do Atendimento Educacional Especializado (AEE), fundamentado e balizado nos marcos legais, políticos e pedagógicos que orientam a implementação de sistemas educacionais inclusivos. Em 2014, institui-se a Sala Multifuncional Bilíngue com o objetivo de melhorar a qualidade do processo de ensino e aprendizagem dos alunos surdos matriculados no CESS, na Educação Básica regular, por meio do apoio pedagógico especializado em turno oposto ao da escolarização. Em 2015, implanta-se a Ação Integral, uma experiência piloto com as turmas do $6^{\circ}$ e $7^{\circ}$ anos do Ensino Fundamental (EF), de segunda a sexta, no contra turno das 13h às 16h. Em 2016, amplia-se o atendimento para as demais 9 turmas do EF II e Ensino Médio, bem como altera-se o horário de atendimento, visando promover o avanço escolar, a autonomia e o protagonismo através de oficinas de artes, capoeira, educação ambiental, esporte e lazer, letramento, liderança surda, matemática, orientação profissional, teatro e xadrez. 
http://dx.doi.org/10.5902/1984686X38499

A AESOS, além de promover a inclusão da pessoa surda, tem como principal missão articular ações de defesa de direitos da Pessoa com Deficiência, visando assegurar a formação educacional dos surdos baianos, bem como promover a inserção da pessoa surda ou com deficiência auditiva no mercado de trabalho. Atualmente, além da cooperação técnica com a Secretaria de Educação do Estado da Bahia (SEC) e com a Secretaria Municipal de Educação de Salvador (SMED), mantém parcerias com a Secretaria Municipal de Promoção Social de Combate à Pobreza (SEMPS) e a Secretaria do Trabalho, Emprego, Renda e Esporte (SETRE).

O Centro Educacional Sons no Silêncio, atuando na perspectiva de uma educação bilíngue (Libras como primeira língua e Língua Portuguesa na modalidade escrita como segunda língua), está atendendo, em 2019, 131 alunos surdos no Ensino Fundamental I e II, Ensino Médio e Educação de Jovens e Adultos - Tempos Formativos I, II e III.

Os anos iniciais do regime de 9 anos de duração estão estruturados por seriação contínua. O Ensino Médio está estruturado em 3 anos consecutivos, a saber: $1^{\circ}, 2^{\circ}$ e $3^{\circ}$ anos. Educação de Jovens e Adultos -O Tempo Formativo (TF) está estruturado em eixos, a saber:

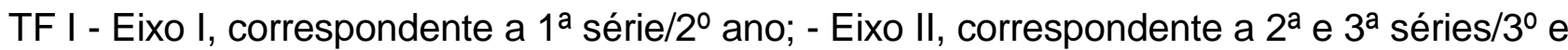

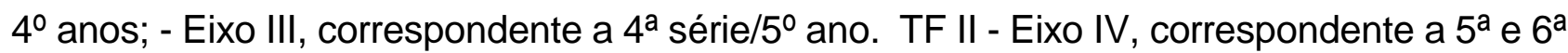
séries $/ 6^{\circ}$ e $7^{\circ}$ anos; - Eixo V, correspondente a $7^{\text {a }}$ e $8^{\underline{a}}$ séries $/ 8^{\circ}$ e $9^{\circ}$ anos. TF III - Eixo VI, correspondente ao $1^{\circ}, 2^{\circ}$ e $3^{\circ}$ anos, área de Linguagens; - Eixo VII, correspondente ao $1^{\circ}$, $2^{\circ}$ e 3ํanos, áreas de Exatas e Linguagens (estas últimas por conta da especificidade dos alunos surdos).

A abordagem metodológica em que se baseia o currículo para a disciplina de Língua Brasileira de Sinais (LIBRAS) para os alunos do Ensino Fundamental está pautada na perspectiva teórico-metodológica da Pedagogia Imagética e Abordagem Sociocultural.

A ementa da disciplina língua portuguesa, na modalidade de segunda língua, tem como objeto de estudo a língua, a literatura e o conteúdo estruturante como discurso, concebendo conhecimento como prática social intercultural, desdobrada em leitura e escrita, considerando o conhecimento prévio do estudante surdo. O objetivo geral é fazer uso da Língua Portuguesa na modalidade escrita como segunda língua (L2), sabendo adequá-la a cada contexto e interlocutor, posicionando-se diante das intenções nos discursos: o assunto tratado, objetivos, entre outros, desenvolvendo a capacidade de pensamento crítico.

Desta forma, ao tentar se qualificar em relação ao oferecimento de uma educação predominantemente bilíngue para o surdo, a AESOS vem contribuindo na preparação do 
http://dx.doi.org/10.5902/1984686X38499

alunado surdo para os processos seletivos de ingresso nas instituições públicas de ensino superior no município, a exemplo do curso Pedagogia Bilíngue online.

É preciso, ainda, aprimorar e intensificar suas ações para que os alunos surdos ali preparados possam se colocar em condições de competir em processos seletivos de acesso ao ensino superior que operam através do sistema de cotas, e não apenas através de projetos específicos de educação para surdo a partir da reserva de vagas, garantidas todas as condições necessárias e previstas por lei.

\section{Considerações finais}

O maior desafio para a elevação geral do nível de escolaridade da população surda baiana e para o acesso de estudantes surdos ao nível superior em instituições públicas de ensino está, basicamente, na criação de políticas linguísticas educacionais institucionais que atendam a particularidade linguística da pessoa surda. Além disso, há a necessidade do comprometimento do Estado, do Sistema Nacional de Educação e da Sociedade Civil, na busca da diminuição das barreiras linguísticas que os estudantes surdos enfrentam, a fim de garantir formas de acesso, com equidade e igualdade, no sistema público baiano.

A AESOS, conforme evidenciado em relação ao ingresso do alunado surdo no Curso Pedagogia Bilíngue, tem-se destacado, nestes últimos anos, como formadora dos estudantes surdos que têm chegado a UFBA, situando-se como relevante ator da Sociedade Civil soteropolitana, mediando e intervindo em ações educacionais, na perspectiva da garantia dos direitos linguísticos da pessoa surda, com vistas a assegurar sua plena inserção na sociedade, bem como na promoção de estratégias pedagógicas no Ensino Médio e na Educação de Jovens e Adultos Surdos.

Para Vieira (2019, p. 25), é a partir do espaço da Sociedade Civil que podemos (re)afirmar as lutas pelos direitos. O autor afirma que a sociedade civil é um "espaço político onde as sociedades contemporâneas podem identificar uma espécie de termômetro das relações sociais, sob ponto de vista de satisfação dos cidadãos em relação às condições econômicas, políticas", educacionais e sociais, percebendo a natureza das relações conflitivas com a possibilidade de intervenção e reconhecimento de direitos e deveres.

Nesse sentido, frente às ações negativas do Estado em garantir o direito a uma educação bilíngue para os estudantes surdos, desresponsabilizando-se do problema social ao não atender à universalização do Direito linguístico da pessoa surda, a atuação da sociedade civil organizada em favor da comunidade surda soteropolitana tem evitado a acentuação da desigualdade e da 
http://dx.doi.org/10.5902/1984686X38499

exclusão social da pessoa surda nos espaços escolares. Não obstante, é preciso maior atenção, ainda, às necessidades educacionais do surdo, no sentido de prepará-lo, de forma adequada, para enfrentar os desafios em relação a seu ingresso no nível superior, em consonância com políticas linguísticas alicerçadas nos pressupostos da pedagogia bilíngue.

Considera-se, como a principal contribuição deste estudo, a visibilidade dada às questões relacionadas à educação dos surdos no que se refere a seu dificultoso acesso ao ensino superior público no município de Salvador. As causas do insucesso do aluno surdo para ingressar no sistema de educação superior parecem estar ligadas a um histórico de vivência escolar que excluiu as pessoas surdas dos processos educacionais/sociais, à inexistência de apoios didáticopedagógicos necessários para realização das provas de ingresso que respeitem sua especificidade linguística comunicacional e às emergentes e tímidas políticas de ação afirmativa que agora começam a ser adotadas.

Esperamos, portanto, que as sinalizações feitas aqui neste estudo sivam de subsídios para a ampliação das discussões em relação à educação dos surdos e, sobretudo, em relação a expansão das condições de acesso e de permanência ofertadas pelas instituições de Ensino Superior ao acolhimento do estudante surdo no município.

\section{Referências}

\section{AESOS. Projeto Político Pedagógico da Associação Educacional Sons no Silêncio (AESOS) e do Centro Educacional Sons no Silêncio (CESS). Salvador, 2019.}

BALDAUF JÚNIOR. Robert. B. Language Planning and Policy: Recent Trends, Future Directions. American Association of Applied Linguistics, Portland, Oregon, v.1-8, p. 1-4 Mai, 2004.

BONACINA-PUGH, Frederick Researching 'praticed language policies': insights from conversation analysis. Language Policy. p. 213-234, 2012.

BRASIL. Lei no. 10.436, de 24 de abril de 2002. Dispõe sobre a Língua Brasileira de Sinais - Libras e dá outras providências. Diário Oficial da União, Brasília, 25 abr. 2002. Disponível em http://www.planalto.gov.br/ccivil_03/leis/2002/L10436.htm. Acesso em 28 de abril de 2016.

BRASIL. Decreto no 5626, de 22 de dezembro de 2005. Regulamenta a Lei $n^{\circ} 10.436$, de 24 de abril de 2002, que dispõe sobre a Língua Brasileira de Sinais - Libras, e o art. 18 da Lei no 10.098, de 19 de dezembro de 2000. Diário Oficial da União Disponível em http://www.planalto.gov.br/ccivil_03/_ato2004-2006/2005/decreto/d5626.htm, Acesso em 28 de abril de 2016. 
http://dx.doi.org/10.5902/1984686X38499

BRASIL. Ministério da Educação. Secretaria de Educação Especial. Política nacional de educação especial na perspectiva da educação inclusiva. Brasília: MEC; SEE, 2008. Disponível em: http://portal.mec.gov.br/arquivos/pdf/politicaeducespecial.pdf. Acesso em: 10 maio. 2019.

BRASIL. Decreto no 6.949, de 25 de agosto de 2009. Promulga a Convenção Internacional sobre os Direitos das Pessoas com Deficiência e seu Protocolo Facultativo. Diário Oficial da União, Brasília, 25 de agosto de 2009. Disponível em: http://www.planalto.gov.br/ccivil_03/_ato2007-2010/2009/decreto/d6949.htm. Acesso em 17 de maio de 2019.

BRASIL. Decreto 7.612, de 17 de novembro de 2011. Institui o Plano Nacional dos Direitos da Pessoa com Deficiência- Plano Viver Sem limite. Diário Oficial da União. Disponível em: http://www.planalto.gov.br/ccivil_03/_ato20112014/2011/decreto/d7612.htm. Acesso em 17 de maio de 2019.

BRASIL. Lei 12.711, de 29 de agosto de 2012 (a Lei de Cotas). Dispõe sobre o ingresso nas universidades federais e nas instituições federais de ensino técnico de nível médio e dá outras providências. Disponível em http://www.planalto.gov.br/ccivil_03/_ato20112014/2012/lei/l12711.htm. Acesso em 10 de maio de 2019.

BRASIL. Lei 13.146, de 06 de julho de 2015. Institui a Lei Brasileira de Inclusão da Pessoa com Deficiência. Disponível em http://www.planalto.gov.br/ccivil_03/_ato2015-

2018/2015/lei/l13146.htm. Acesso em 10 de maio de 2019.

BRASIL. Lei 13.409, de 28 de dezembro de 2016. Dispõe sobre a reserva de vagas para pessoas com deficiência nos cursos técnico de nível médio e superior das instituições federais de ensino. Disponível em https://www2.camara.leg.br/legin/fed/lei/2016/lei-1340928-dezembro-2016-784149-publicacaooriginal-151756-pl.html. Acesso em 10 de maio de 2019.

CERETTA, Laura Moreira; FERNANDES, Sueli. Acesso e permanência de estudantes surdos no Ensino Superior. Palestra apresentada na Mesa 02: "Ingresso e Permanência dos Estudantes Surdos nas IES”, em I SIES: Trajetória do Estudante Surdo, 26 e 27 de maio de 2008 / Londrina - PR.

ESDRAS, Dirceu; GALASSO, Bruno. Panorama da educação de surdos no Brasil: ensino superior. Instituto Nacional de Educação de Surdos(Org.). Rio de Janeiro: INES, 2017.

FERREIRA, Maria Cecília Carareto; ZAMPIERI, Marinês Amalia. Atuação do professor ouvinte na relação com o aluno surdo: relato de experiência nas séries iniciais do ensino fundamental. In: LODI, A. C. B.; LACERDA, C. B. F, de. Uma escola, duas línguas. Porto Alegre: Mediação, 2010. 
http://dx.doi.org/10.5902/1984686X38499

HERMANS, Daan; KNOORS, Harry; ORMEL, Ellen \& VERHOEVEN, Ludo. The Relationship between the Reading and Signing Skills of Deaf Children in Bilingual Education Programs. The Journal of Deaf Studies and Deaf Education, Volume 13, Issue 4, Fall 2008, 518-530. https://academic.oup.com/jdsde/article/13/4/518/497665.

INES. Projeto Institucional de Educação a Distância. Rio de Janeiro, 2015. http://neo.ines.gov.br/neo/images/pdf/projeto-institucional-ead-ines.pdf.

LODI, Ana Claudia Balieiro. Educação bilíngue para surdos e inclusão segundo a Política Nacional de Educação Especial e o Decreto n0 5.626/05. Educ. Pesqui., São Paulo, v. 39, n. 1, p. 49-63, jan./mar. 2013. http://www.scielo.br/pdf/ep/v39n1/v39n1a04.pdf.

LODI, Ana Claudia Baileiro; LACERDA, Cristina Broglia Feitosa de de. (Orgs.) Uma escola, duas línguas: Letramento em língua portuguesa e língua de sinais nas etapas iniciais de escolarização. Porto Alegre: Mediação, 2010.

MARTINS, Diléia Aparecida e LACERDA, Cristina Broglia Feitosa. Exame Nacional do Ensino Médio e acesso de estudantes surdos ao Ensino Superior Brasileiro. Pro-Posições, v. 26 , n. 3 (78), p. 83-101, set./dez. 2015.

MARTINS, Diléia Aparecida; LEITE, Lúcia Pereira e LACERDA, Cristina Broglia Feitosa. Políticas públicas para acesso de pessoas com deficiência ao ensino superior brasileiro: uma análise de indicadores educacionais. Ensaio: aval.pol.públ.Educ., Dez 2015, vol.23, no.89, p.984-1014.

MEC/SECADI - Relatório do Grupo de Trabalho, designado pelas Portarias $\mathrm{n}$ ำ.060/2013 e no91/2013, contendo subsídios para a Política Linguística de Educação Bilíngue - Língua Brasileira de Sinais e Língua Portuguesa Brasília, DF, 2014.

MAYER, Connie \& AKAMATSU, Tane. Bilingual-Bicultural Models of Literacy Education for Deaf Students: Considering the Claims. Journal of Deaf Studies.

NAPE/PROAE/UFBA. Relatório Interno do Núcleo de Apoio à Pessoa com Necessidades Especiais. Universidade Federal da Bahia. Salvador. 2018.

NAPE/PROAE/UFBA. Relatório Interno do Núcleo de Apoio à Pessoa com Necessidades Especiais. Universidade Federal da Bahia. Salvador. 2019/1.

OLIVEIRA, Gilvan Müller de. Políticas Linguísticas: uma entrevista com Gilvan Müller de Oliveira. ReVEL, v. 14, n. 26, 2016. [www.revel.inf.br].

POLO UFBA - Curso Letras Libras. Relatório — Turma 2006-2010. Salvador, Universidade Federal da Bahia, 2010.

POLO UFBA - Curso Letras Libras. Relatório — Turma 2008-2012. Salvador, Universidade Federal da Bahia, 2012.

POLO UFBA - Curso Pedagogia Bilíngue Relatório — Turmas 2018 e 2019. Salvador, Universidade Federal da Bahia, 2019. 
http://dx.doi.org/10.5902/1984686X38499

QUADROS, Ronice Muller. O "Bl" em bilinguismo na educação de surdos. In: LODI, A. C. B.; A B.; MÉLO, A. D.B. e FERNANDES, E. (Orgs). Letramento, bilinguismo e educação de surdos. Porto Alegre: Editora Mediação. 2012. p. 187 a 200. 2013.

QUADROS, Ronice Muller (Org.) Letras LIBRAS: ontem, hoje e amanhã - Florianópolis: Ed. da UFSC, 2014.

REBOUÇAS, Larissa. S. A Prioridade dos Docentes Surdos para Ensinar a Disciplina Língua Brasileira de Sinais (Libras) nas Instituições de Ensino Superior após o Decreto 5.626/2005. Dissertação de Mestrado em Educação. Salvador: Universidade Federal da Bahia, 2009. Disponível em: http://editora-araraazul.com.br/cadernoacademico/Dissertacao_de_Mestrado_de_LARISSA_REBOUCAS.pdf.

ROSA, Emiliana. F. Olhares sobre si: a busca pelo fortalecimento das identidades surdas. Dissertação de Mestrado em Educação. Salvador: Universidade Federal da Bahia, 2009. Disponível em:

http://www.dominiopublico.gov.br/pesquisa/PesquisaObraForm.do?select_action=\&co_autor $=82777$.

TEIXEIRA, Elizabeth; MARINHO, Erivaldo. O letramento de surdos em escolas especiais em Salvador. In Theresinha Guimarães MIRANDA e Teófilo Alves GALVÃO (Orgs.) 0 professor e a educação inclusiva: formação, práticas e lugares. Salvador: EDUFBA, 2012. 445-454.

VIEIRA. Roberto Carlos. Organizações da Sociedade Civil: conformação e resistência ao ideário neoliberal. Tese de Doutorado. Universidade Católica do Salvador, 2019.

UNIVERSIDADE FEDERAL DA BAHIA. Relatório Ilustrado: 2014-2017, 2018a.

UNIVERSIDADE FEDERAL DA BAHIA. Retrospectiva Especial: 70 Anos, 2016.

UNIVERSIDADE FEDERAL DA BAHIA. UFBA em números: Ano base 2017, 2018b.

\section{Notas}

1 Sigla proveniente do termo inglês "Children of Deaf Adults".

\section{Correspondência}

Elizabeth Reis Teixeira - Universidade Federal da Bahia - Ondina, Instituto de Letras, Av. Barão de Germoabo, n. 147, Salvador, Bahia - Brasil. CEP: 40110-909.

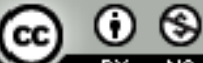

4.0 International (CC BY-NC 4.0). 